\title{
Inhibitory control of memory in normal aging: Dissociation between impaired intentional and preserved unintentional processes.
}

\author{
Fabienne Collette $^{1,2}$, Sophie Germain ${ }^{1}$, Michaël Hogge ${ }^{1}$, Martial Van der Linden ${ }^{1,3}$ \\ ${ }^{1}$ Cognitive and Behavioural Neuroscience Centre, University of Liège, Liège, Belgium \\ ${ }^{2}$ Cyclotron Research Centre, University of Liège, Liège, Belgium \\ ${ }^{3}$ Cognitive Psychopathology Unit, University of Geneva, Geneva, Switzerland
}

\begin{abstract}
The aim of this study was to compare the performance of elderly and young participants on a series of memory tasks involving either intentional or unintentional inhibitory control of memory content. Intentional inhibition processes in working and episodic memory were explored with directed forgetting tasks and in semantic memory with the Hayling task. Unintentional inhibitory processes in working memory, long-term memory and semantic memory were explored with an interference resolution task, the retrieval practice paradigm and the flanker task, respectively. The results indicate that elderly subjects' performance on the two directed forgetting tasks and the Hayling task is lower than that of young ones, and that this impairment is not related to their initial memory capacity. This suggests that there is a specific dysfunction affecting intentional inhibitory control of memory contents in normal aging.
\end{abstract}

\section{Acknowledgements}

F. Collette is Senior Research Associate and M. Hogge is Research Fellow at the National Fund for Scientific Research (FNRS) of Belgium. This study was supported by the FNRS, the University of Liège, the InterUniversity Attraction Pole P 6/29 and the Government of the French-Speaking Community of Belgium (Actions de Recherches Concertées, Grant 05-10-332).

Corresponding author: Fabienne Collette, Neuropsychology unit, Boulevard du rectorat 3 (B33), 4000 Liège, Belgium, Phone: 32436622 74, Fax: 32436628 75, Email: f.collette@ulg.ac.be 
Published in : Memory (2009), 17(1), 104-122

Status : Postprint (Author's version)

\section{Introduction}

It is now widely acknowledged that, as adults age, they experience deficits in various cognitive domains. A number of interpretations have been proposed to explain age-related differences in cognitive functioning, such as a decline in processing speed, working memory capacity, the efficiency of inhibitory processes and even the integrity of sensorimotor functioning. However, it is not yet clear how much each of these factors contributes to the effect of aging on cognition (see for example, Kwong See \& Ryan, 1995; Park et al., 1996; Salthouse, 1996; Van der Linden et al., 1999).

Among age-related cognitive changes, deficits are particularly salient in the memory domain (for a review, see Zacks, Hasher, \& Li, 2000). One prominent explanation of the reduced memory performance in elderly subjects is the inhibition-deficit account, which argues that, compared to young adults, older adults have spared excitatory attentional mechanisms but less efficient inhibitory mechanisms (Hasher \& Zacks, 1988). As a result, memory deficits may arise because irrelevant material occupies resources in working memory that would otherwise be available for the processing of task-relevant information. In agreement with the inhibition-deficit hypothesis, it is now widely acknowledged that elderly people present inhibitory dysfunctions on a wide variety of tasks including perception (Houx, Jolles, \& Vrieling, 1993; Spieler, Balota, \& Faust, 1996), language (Andrès \& Van der Linden, 2000; Connelly, Hasher, \& Zacks, 1991; Hartman \& Hasher, 1991) and motor processes (Butler, Zacks, \& Henderson, 1999; May \& Hasher, 1998; Nielson, Langenecker, \& Garavan, 2002). Interestingly, larger inhibitory effects have frequently been observed in older participants during performance on memory tasks that require the suppression of some information or resistance to interference. One way to explore the influence of inhibition abilities on memory performance is to use directed forgetting tasks. In these tasks, information that subjects have to process are first presented and next followed by a cue indicating if the information must (or not) be kept in memory for later recall or recognition. Thus, greater directed forgetting effects were reported in elderly than young subjects with working memory (Andrès, Van der Linden, \& Parmentier, 2004) and episodic memory tasks when the item method (in which the "remember" or "forget" cue directly follows the presentation of each item) of the directed forgetting paradigm was used (Earles \& Kersten, 2002; Gamboz \& Russo, 2002; Hogge, Adam, \& Collette, 2008; Sego, Golding, \& Gottlob, 2006; Zacks, Radvansky, \& Hasher, 1996, experiment 1) but not when the list method (in which the cue is presented after the whole list of items) was used (Sego et al., 2006; Zellner \& Bäuml, 2006; see, however, Zacks et al., 1996, experiment 2). Otherwise, studies that measured inhibitory effects in memory using the fan effect (e.g., Anderson, 1974) demonstrated that the retrieval of previously learned memories in older adults is slowed by the enrichment of target information with irrelevant associations (Radvansky, Zacks, \& Hasher, 1996, 2005). However, in another task assessing the automatic inhibition of irrelevant information that is semantically related to the target information (the retrieval-induced forgetting paradigm; Anderson, Bjork, \& Bjork, 1994), similar degrees of inhibition were observed in young and elderly subjects (Aslan, Bäuml, \& Pastötter, 2007; Hogge, Adam, \& Collette, in press a). Similarly, the part-set cuing effect (namely, the detrimental effect that presenting a subset of to-be-remembered items as cues for retrieval has on recall) was found preserved in normal aging (Andrès, in press; Marsh, Dolan, Balota \& Roediger, 2004)

Taken as a whole, results of these studies indicate that inhibitory abilities have a direct influence on the capacity of healthy elderly subjects to efficiently control the contents of one's memory (e.g., discarding information when it is no longer relevant or maintaining previously presented information in an accessible state during the processing of other information). However, since these effects were found using a range of tasks in different groups of subjects, no firm conclusions can be drawn from these studies regarding why an inhibitory effect was not systematically observed. To date, the study by Salthouse, Siedlecki, and Krueger (2006) is the only one that explored the influence of inhibitory functioning on the memory performance of elderly subjects using a wide variety of tasks (e.g., multiple trial recall with an interpolated interference list, directed forgetting, proactive interference and retrieval inhibition). Salthouse et al. hypothesized that the poorer performance of elderly subjects previously observed on these tasks 
stems from their generally poorer inhibitory control over the contents of memory. However, although the results obtained in young and elderly subjects replicated most of the patterns from earlier studies, the authors failed to observe a single memory control ability that might explain the elderly subjects' poorer performance in the tasks administered.

It must nevertheless be emphasized that, due to the difficulty to locate explicit references to a single construct concerned with controlling the contents of one's memory, Salthouse et al. (2006) selected a series of tasks that were not described in the literature as requiring memory control but rather as requiring executive attention and/or executive processes. Consequently, the authors considered executive processes and controlled attention to have a common influence on the various measures hypothesized to reflect memory control. More precisely, the role of these executive processes in the tasks administered was to resist interference, to suppress no-longer-relevant information, and to inhibit possible competitors at the time of retrieval (e.g., Anderson, 2003; Bjork, 1998; Engle \& Kane, 2004; Kane \& Engle, 2000). However, beyond the intervention of some common executive processes, the tasks selected differ in terms of the exact characteristics of the inhibitory processes involved. Indeed, some tasks were considered as requiring inhibition at the time when information is encoded or rehearsed (i.e., the directed forgetting task with the item method; MacLeod, 1998) and others when it is retrieved (i.e., the retrieval-induced forgetting paradigm; Anderson, 2003). Moreover, sometimes subjects were explicitly told to suppress specific information (i.e., the directed forgetting task), while in other tasks no mention was made of the presence of distracting information (i.e., resistance to proactive interference). Consequently, it could be considered that inhibitory memory control does not refer to a single cognitive construct but rather that a series of distinct inhibitory processes are associated with the control of memory contents, depending the exact requirements of the tasks, and that these processes are differentially affected by normal aging.

In agreement with the proposal of specific inhibitory dysfunctions in normal aging, studies that have simultaneously explored the integrity of several inhibitory processes in a single group of elderly subjects (Andrès, Guerrini, Phillips \& Perfect, 2008; Charlot \& Feyereisen, 2005; Kramer, Humphrey, Larish, Logan, \& Strayer, 1994) demonstrated that not all inhibitory tasks were impaired in normal aging. Moreover, studies exploring inhibitory functioning in elderly subjects using verbal memory tasks do not systematically report impaired performance (i.e., Aslan et al., 2007; Sego et al., 2006; for examples of impaired performance see however Andrès et al., 2004; Radvansky et al., 1996, 2005).

From a theoretical viewpoint, a distinction has been proposed in the literature between intentional and unintentional inhibitory processes (Harnishfeger, 1995; see also Nigg, 2000). According to Harnishfeger, unintentional inhibition occurs prior to conscious awareness and refers to a kind of attentional processing that is used to 'gate' which information will enter consciousness. Examples of experimental paradigms involving this kind of inhibition are the resolution of lexical ambiguity (e.g., Swinney \& Prather, 1989) and retrieval-induced forgetting (e.g., Anderson et al., 1994) tasks. In these tasks, inhibition represents the suppression of a previously activated cognitive content that appears to occur automatically and without intention or awareness. Conversely, intentional inhibition is a process that is deliberately invoked to deal with irrelevant stimuli, from internal or external sources. Examples of tasks that involve intentional inhibition are the directed forgetting (Johnson, 1994) and thought suppression paradigms (Anderson \& Green, 2001). In such paradigms, inhibition refers to the conscious and voluntary suppression from working memory of stimuli that become irrelevant for the ongoing task. Data that support this theoretical distinction can be found in studies of child development. For example, first- and third-grade children fail to show directed forgetting, though normal directed forgetting performance is present from fifth grade on (Harnishfeger \& Pope, 1996); however, this developmental trend was not found for unintentional inhibitory tasks such as the retrieval-induced forgetting paradigm (Lechuga, Moreno, Pelegrina, Gomez-Ariza, \& Bajo Teresa, 2006).

On the basis of the theoretical framework proposed by Harnishfeger (1995), the absence of a single general memory control ability that might explain the poorer performance of elderly subjects in the Salthouse et al. (1996) study could be due to the administration of tasks requiring either intentional or unintentional inhibitory control of memory contents. Consequently, in the present study, we were interested to determining whether one of these two inhibitory processes might be preserved in normal 
Published in : Memory (2009), 17(1), 104-122

Status : Postprint (Author's version)

aging. We administered a series of tasks that Harnishfeger explicitly declared to require intentional or unintentional inhibition (directed forgetting tasks vs. retrieval inhibition paradigm), or that can be considered, on the basis of task analyses, to depend on one of these two kinds of memory control (intentional: the Hayling task; unintentional: the flanker and probe recency tasks). In agreement with Harnishfeger's proposal, participants are explicitly warned in the tasks requiring intentional inhibitory processes that they do not have to recall or produce certain information, while no mention was made of the presence of irrelevant information in the tasks requiring unintentional inhibition. Each kind of inhibitory control process was explored in the domains of working memory, episodic memory and semantic memory.

We predicted that intentional inhibitory control processes would be specifically impaired in the group of elderly subjects whatever the memory domain. Indeed, a dominant hypothesis to explain the cognitive changes associated with normal aging is that the cognitive resources available to perform mental operations decrease with age (Park \& Hedden, 2001). Since intentional inhibitory control of memory can be considered to place a high demand on attentional resources (see, for example, Conway, Harries, Noyes, Racsma'ny, \& Frankish, 2000, experiments 2, 3, and 4), we expected that elderly subjects' inhibitory performance would be reduced (in comparison to that of young subjects) in the three memory tasks requiring intentional suppression of some information, but that the two groups would perform similarly on tasks requiring unintentional inhibitory processes.

\section{Method}

Subjects

Eighty adults volunteered to participate in this study. All subjects had normal or corrected vision and normal or corrected hearing. The 40 younger adults (19 men and 21 women) had an average age of 24.15 \pm 1.69 years (range $=21-27$ ). The 40 elderly subjects ( 21 men and 19 women) had an average age of $67 \pm$ 5.12 years (range $=60-75$ ). All participants were native speakers of French and none reported any medical, neurological or sensory defects, or use of medication likely to alter cognitive functioning. To assess crystallized verbal ability, the Mill-Hill Vocabulary Scale (multiple-choice form; a Frenchlanguage adaptation by Deltour, 1993) was administered to all participants. No significant difference was found between the scores of the younger (36.6 \pm 3.6$)$ and older $(37.52 \pm 5.7)$ subjects $[t(78)=0.88, p>$ .1]. The elderly participants were also given the Mattis Dementia Rating Scale (Mattis, 1973), which is widely used to screen for dementia. All subjects had a total score superior to 130 on this scale, which constitutes the cut-off score frequently used to discriminate normal aging from dementia (Monsch et al., 1995).

\section{Procedure and overall design}

The tasks described in the present study were part of a larger battery designed to explore inhibitory functioning in normal aging. The participants were tested individually in a quiet room in two separate oneand-a-half-hour sessions that took place over a few days. Most of the tasks were presented on a microcomputer. In order to avoid practice and weariness effects, two orders for the administration of the tasks were defined and were randomly assigned to participants. Computerized tasks were presented on a PC-compatible computer interfaced with a 14-inch SVGA colour monitor using E-Prime software version 1.0 (Schneider, Eschman, \& Zuccolotto, 2002). Participants were seated in front of the computer screen so that their eyes were approximately $50 \mathrm{~cm}$ from the display. Accuracy of responses and response times were recorded using an AZERTY keyboard.

Six tasks assessing inhibitory memory control were administrated. Three of them required intentional inhibitory control (short term and long term directed forgetting and Hayling tasks) and the three others unintentional inhibition (probe recency, retrieval induced forgetting and flanker tasks). The (un)intentionality of inhibitory control was assessed in the domains of working memory (short-term directed forgetting vs. probe recency tasks), episodic memory (long-term directed forgetting vs. retrieval induced forgetting tasks) and semantic memory (Hayling vs. Flanker tasks). 
Published in : Memory (2009), 17(1), 104-122

Status : Postprint (Author's version)

\section{Cognitive tasks}

Intentional inhibitory memory control

Short-term directed forgetting task (working memory)

We used a procedure adapted from Reed's (1970) study and similar to that used by Andrès et al. (2004). In this task, trigrams composed of consonants were presented for 2,000 milliseconds on a computer screen and subjects were asked to read aloud and memorize the trigrams presented. Three experimental conditions were administered. In the single-trigram condition (control condition), a single trigram (three consonants) was presented for retention. In the retroactive interference condition, a second (interfering) trigram was presented for retention immediately after the first one. In the directed forgetting (or inhibition) condition, two trigrams were also presented consecutively. However, immediately after the presentation of the second trigram, a screen displayed the message 'to be forgotten' for 500 milliseconds, which prompted participants to forget the trigram as they would not be required to recall it later. Immediately after the presentation of the trigram(s), an interpolated activity was presented that consisted of reading strings of numbers aloud for 10 seconds. Next, the participants were asked to recall the three letters of the trigram(s) in order (with no time constraint). In the inhibition condition, only the first trigram had to be recalled while in the interference condition, subjects had to recall the first and second trigrams. Three practice trials, one per condition, were given prior to the beginning of the task. Participants were then presented with 30 trials, 10 per experimental condition, and these trials were randomly presented in the same pre-established order for all participants.

Participants' responses were scored following Reed's criterion (1970) by assigning one point for each letter recalled (regardless of its position within the trigram) and an additional point when this letter was recalled in its correct position (maximum score per condition was therefore 60). In the retroactive interference condition (i.e., presentation of a second, interfering trigram), only recall of the first trigram was scored (as in the inhibition condition). Sensitivity to retroactive interference was measured by the difference in performance between the single-trigram and retroactive interference conditions. Inhibitory capacity was measured by the difference in recall performance between the single trigram and directed forgetting conditions (Andrès et al., 2004).

\section{Long-term directed forgetting task ${ }^{1}$ (episodic memory)}

This task is a French adaptation of the procedure used by MacLeod (1989, experiment 2). The material consisted of 36 six-letter words selected from the Brulex French database (Content, Mousty, \& Radeau, 1990). These items were randomly attributed to two categories of 18 words, matched for word frequency $[t(22)=0.08 ; p=.93]$ : (1) items belonging to the category of the words that must be remembered (to-beremembered or TBR items); (2) items belonging to the category of the words that must be forgotten (tobe-forgotten or TBF items). Allocation of items to the TBR and TBF categories was counterbalanced in order to create two versions of the task, which were administered to subjects randomly.

In the learning phase, 36 words were individually presented on the centre of a computer screen for 3 seconds. Each was followed by either a remember ('to remember') or a forget ('to forget') cue that remained on the screen for 3 seconds too. Subjects were asked to read each word aloud and to remember only the words followed by a remember cue (while attempting to forget any word followed by a forget cue). Prior to the beginning of the task, it was stressed that the memory test would only be based on the TBR words. After the learning phase, subjects were asked to perform a distraction task that consisted of counting backward in increments of 3 for 30 seconds.

In the recall task phase, participants were asked to orally recall all words that had been presented during the learning phase. Participants' responses were scored by assigning one point for each item recalled, that the item had been previously presented as 'to-be-remembered' (TBR) or 'to-be-forgotten' (TBF) in the learning phase. The production of a TBF item during the recall phase reflects a failure to efficiently inhibit this word since its representation remained active (that the subjects consciously remember or not the TBF status of the item). Inhibitory abilities were determined by comparing recall 
Published in : Memory (2009), 17(1), 104-122

Status : Postprint (Author's version)

performance for the TBR and TBF items, with the recall of a larger number of TBF items by comparison to TBR items indicating low inhibitory abilities.

\section{Hayling task (semantic memory)}

This task assesses the capacity to suppress (inhibit) a habitual response and was initially devised to examine both initiation and inhibition processes (Burgess \& Shallice, 1996). The French version of the task developed by Andrès and Van der Linden (2000) was used. The Hayling task consists of 30 sentences in which the final word is omitted but has a particularly high probability of one specific response. The task is composed of two sections (A and B), each containing 15 sentences. In section A (initiation), sentences are read aloud by the examiner to subjects, who have to complete each sentence with the missing word. In section B (response suppression), sentences are again read aloud by the examiner to subjects who now have to complete the sentence not with the expected word but with a word unrelated to the sentence. Response times were recorded by stopwatch and correspond to the interval between the last word produced by the examiner ant the production of a response by the subject. If at any time during this stage of the test, subjects give a sentence completion rather than an unrelated word, they are told that the word is too closely related to the sentence, and the task instructions are repeated. If a subject does not produce a word within 30 seconds, that trial is terminated and a response latency of 30 seconds is recorded. Different measures of response suppression abilities were used in the analysis. First, section B latencies minus section A latencies were considered for each subject, which presumably represents the additional thinking time required in having to produce a novel word rather than a straightforward sentence completion. Secondly, a semantic score was devised for section B whereby the overall semantic relationship of each response to its stimulus sentence was measured: three points were given if the word was a straightforward completion of the sentence, one point for a word semantically related to the sentence in some way and no score when the response successfully fulfilled the task requirements (namely, no relationship was found between the word produced and the remainder of the sentence).

Measures of initiation of response consisted of mean response times in part A of the task. Measures of inhibition consisted of the raw response latency (mean latencies across 15 trials) when the suppression time was controlled for the initiation time (namely, RTs $[(\mathrm{B}-\mathrm{A}) /(\mathrm{B}+\mathrm{A})]$ ) and the semantic score (measuring the overall semantic relatedness of the responses to the sentence).

\section{Unintentional inhibitory memory control}

Probe recency recognition task (working memory)

The design of this task was similar to that used in neuroimaging studies by Jonides, Smith, Marshuetz, Koeppe, and Reuter-Lorenz (1998) and D'Esposito, Postle, Jonides, and Smith (1999). Each subject completed 80 trials of an item recognition memory task (four sessions of 20 trials separated by short rest periods) in which they were required to judge whether a test probe item was a member of a set of previously studied items. In each trial, four consonants were simultaneously presented in the centre of a computer screen for 1,500 milliseconds. After a retention delay of 3,000 milliseconds, the probe letter was presented and the subjects had to decide, and indicate by a key press, whether the probe was one of the four letters previously presented in that trial. The probe letter remained displayed for a maximum of 2,000 milliseconds or until the subject responded. Practice trials were administered before the beginning of each session. The task was composed of four conditions: (1) Recent Negative trials, in which the probe did not match any items in the target set of the present trial but did match an item from the target set of one of the two previous trials (and thus required a 'no' response); (2) Nonrecent Negative trials, in which the probe matched items from neither the current nor the two previous target sets (and thus required a 'no' response); (3) Recent Positive trials, in which the probe matched an item that was presented in the current target set (and thus required a 'yes' response) and in one of the two previous target sets; and (4) Nonrecent Positive trials, in which the probe matched an item that was presented in the current target set (and thus required a 'yes' response) but not in either of the two previous target sets. The four kinds of trials were randomly administered across the four sessions, with the restriction that no more than three trials of the 
Published in : Memory (2009), 17(1), 104-122

Status : Postprint (Author's version)

same type were presented in succession (the order of presentation being similar for all subjects). Subjects were not informed about the manipulation of probe recency.

Median response times (RT) and accuracy of responses in the four conditions (Nonrecent Negative, Recent Negative, Nonrecent Positive, Recent Positive) were compared between the two groups of subjects. The critical features of behavioural performance concern the comparison of the Recent Negative trials to the Nonrecent Negative trials (inhibition effect) and the comparison of the Recent Positive trials to the Nonrecent Positive trials (facilitation effect).

\section{Retrieval-induced forgetting task (episodic memory)}

This task was adapted from Anderson et al. (1994). The material consisted of 16 exemplars of two taxonomic categories (birds and musical instruments) that were drawn from the category norms made by Dubois (1982) for French. Eight strong and eight weak exemplars were chosen from each of the categories. Care was taken to ensure that none of the exemplars of a specific category shared the same two first letters. At the retrieval practice phase, eight exemplars were practised from one of the two categories. No items were practised from the remaining category. Thus, there were, eight practised items from practised categories (RP+), eight unpractised items from practised categories (RP-) and 16 unpractised items (U).

Subjects were told that they would participate in a memory test on a computer screen and they were shown an example of the test category-exemplar pairs (e.g., Bird - crow). Participants were instructed to learn the pairs for an upcoming test and it was stressed that the category cue was displayed to promote this learning. At the study phase, subjects learned the 32 exemplars belonging to two semantic categories. Items were presented in a pseudo-random order, one pair at a time, in a category-exemplar paired associate format for 5 seconds. The inter-stimulus interval was set at 1.5 seconds. At the retrieval practice phase, participants practised retrieval for half of the exemplars of half of the categories. That is, they were told to retrieve specific exemplars based on their first two letters displayed along with their category cue (e.g., Bird - cr___ ). First, the category cue appeared alone on the screen for 2 seconds; it was then accompanied by the first two letters of an exemplar, which remained on the screen just below the category cue for 10 seconds. Participants responded orally, and the correct response was displayed on the screen once they had done so. This retrieval practice procedure was repeated three times with the same exemplars, but in a random fashion. After a retention interval of 15 minutes, participants completed the final memory test. They were instructed to verbally recall as many of the exemplars as they could remember from each category. They were cued for each category using the category name. Recall from the categories was in a counterbalanced order; thus, across participants, there were equal numbers recalling an unpractised or a practised category first.

Participants' responses were scored by assigning one point for each target exemplar that was correctly recalled. Inhibitory abilities were determined by comparing performance for the RP- items in comparison to $U$ items, while the comparison of $U$ and $R P+$ items reflected the effects of practice.

\section{Flanker task (semantic memory)}

This task was adapted from Shaw (1991). The material consisted of 16 target words (8 metal words and 8 furniture words) and 16 neutral flanker items (8 vehicles and 8 fishes) selected from the Brulex French database (Content et al., 1990) and representing the most frequent category exemplars. The mean number of graphemes in the words in each of the four categories was similar $[F(1,12)=0.05 ; p>.9]$. In each trial, the stimuli were three words (one central target and two flankers) presented in a single column in uppercase letters on a computer screen. The task was described to participants as a study of reading and categorization of the centrally presented information and they were told not to pay any attention to the flanker words. The subjects were given 128 trials in four sessions of 32 trials each, separated by short rest periods. Practice trials were administered before the beginning of each session. At the outset of each trial, a blinking arrow appeared for 600 milliseconds in the location in which the first letter of the target word was to appear. As the fixation point disappeared, it was immediately replaced by the target and flanker words. These stimuli were removed immediately after the participant responded. On each appearance, the 
Published in : Memory (2009), 17(1), 104-122

Status : Postprint (Author's version)

target word was flanked, above and below, by an additional word. Participants pressed one of two response keys to indicate the category of each target word. Each of the four experimental conditions was determined by the relation between the target and flanker words. For two of the conditions, the target and flanker words were associated with compatible responses (namely, the same response key): in the sameword (SW) condition, the flanker and target words were identical; in the same-category (SC) condition, the target and flanker words were two exemplars of the same category. In the third, or neutral-response (NR) condition, the flanker was one of the neutral words (and thus was not associated with any response key). In the different-response (DR) condition, the target and flanker words were from different target categories and were therefore associated with incompatible responses (the target and flanker words were associated with different response keys).

Statistical analyses were performed by grouping together the two facilitation conditions (same word and same category) involved in Shaw's (1991) initial task. This was done to obtain measures of semantic inhibition and facilitation that could easily be compared to those obtained in the task of interference in working memory (probe recency task).

\section{Results}

Statistical analyses consisted of two-way ANOVAs on the groups of young and elderly participants. A statistical level of $p<.05$ was used for all analyses. When significant effects were observed, planned comparisons were next performed, also with a statistical level of $p<.05$. Inhibitory abilities were measured by both median response times and response accuracy. The effect size of each analysis was reported as partial eta square (ES) for the main effects and the interactions, and as Cohen's D $(d)$ for planned comparisons. Partial eta square is generally interpreted as the proportion of variance of the dependent variable that is related to the factor. Traditionally, eta square values of $.01, .06$, and .14 and $d$ values of .2, .5, and .8 represent small, medium and large effect sizes, respectively (Cohen, 1988).

\section{Intentional inhibitory memory control \\ Short-term directed forgetting task}

The performance of the two groups of subjects in the different conditions is presented in Table 1 . A 2 (group: young, elderly) X 3 (condition: control, retroactive interference, inhibition) ANOVA was done, and demonstrated a significant group effect $[F(1,78)=9.83, p<.0005$, ES $=.11]$, with better performance by young than elderly participants; there was also a significant condition effect $[F(2,156)=140.50, p<$ .0001 , ES $=.57$ ], with better performance in the single trigram condition than in the inhibition condition and better performance in the inhibition condition than in the retroactive interference condition. Finally, a significant interaction between group and condition was also found $[F(2,156)=3.88, p<.05, \mathrm{ES}=.042]$. Planned comparisons revealed a similar decrease in performance in young and elderly subjects between the single trigram and retroactive interference conditions $[F(1,78)=2.08, p>.05, d=.46]$, as well as a similar increase in performance between the retroactive interference and inhibition conditions $[F(1,78)=$ $0.90, p>.05, d=.21]$. However, the comparison of the single trigram condition to the inhibition condition demonstrated a greater decrease in performance in elderly participants than in young subjects $[F(1,78)=$ 8.36, $p<.005, d=.91$ ]. The directed forgetting effect was also measured by directly subtracting performance in the DF condition from that in the control condition. This difference was smaller in the elderly than in the young participants $[F(1,78)=9.74, p<.005$, ES $=.11]$. 
Published in : Memory (2009), 17(1), 104-122

Status : Postprint (Author's version)

Table 1. Short term directed forgetting task. Percentage of correct responses

[mean (standard deviation)] as a function of group and condition.

\begin{tabular}{|l|c|c|}
\hline & Young subjects & Elderly subjects \\
\hline Control condition & $91.17(10.29)$ & $86.72(19.64)$ \\
\hline Retroactive interference condition & $70.46(18.40)$ & $59.91(22.56)$ \\
\hline Inhibition condition & $83.54(13)$ & $70.93(27.64)$ \\
\hline Directed forgetting effect & $7.62(10.03)$ & $15.92(13.11)$ \\
\hline
\end{tabular}

Long-term directed forgetting task

The performance of the young and elderly subjects for the TBR and TBF items is presented in Table 2 . The directed forgetting effect was assessed with a 2 (group: young, elderly) X 2 (condition: TBR, TBF) ANOVA with condition as a repeated measures factor. The analysis revealed a significant group effect $[F(1,78)=27.56, p<.0001$, ES $=.26]$, with lower recall performance in elderly than young participants, and a significant condition effect $[F(1,78)=105.02, p<.0001$, ES $=.57]$, with fewer TBF items than TBR items recalled. Finally, a significant interaction effect between group and condition was also observed $[F(1,78)=4.75, p<.05$, ES $=.057]$. Planned comparisons demonstrated that, although the directed forgetting effect was present in both groups [young: $F(1,78)=77.22, p<.0001, d=1.96$; elderly: $F(1,78)$ $=32.55, p<.0001, d=1.27$, it is reduced in elderly participants by comparison to young ones $(d=.68)$.

Table 2. Long-term directed forgetting task. Percentage of correct responses [mean (standard deviation)] as a function of group and condition.

\begin{tabular}{|l|c|c|}
\hline & Young subjects & Elderly subjects \\
\hline TBR items & $42.30(13.64)$ & $26.94(14.75)$ \\
\hline TBF items & $18.13(13.44)$ & $11.25(8.76)$ \\
\hline Directed forgetting effect & $24.17(16.67)$ & $15.69(18.06)$ \\
\hline
\end{tabular}

Hayling task

The results for the two groups of subjects are presented in Table 3. The comparison of response times for Part A (requiring only initiation of response) showed a significant difference between the two groups $[F(1,78)=4.97, p<.05, \mathrm{ES}=.060]$, with elderly subjects being slower than young subjects. With regard to the inhibition portion, the comparison of RTs $[(B-A) /(B+A)]$ revealed no significant differences between groups $[F(1,78)=2.87, p>.05$, ES $=.035]$. However, the semantic relatedness of responses made in Part B differed for the two groups $[F(1,78)=20.10, p<.0001$, ES $=.20]$, with more semantic relatedness in the group of elderly participants.

Table 3. Hayling task. Response time (in seconds; [mean (standard deviation)]) and accuracy of response (mean \pm standard deviation) as a function of group and part of the task

\begin{tabular}{|l|c|c|}
\hline & Young subjects & Elderly subjects \\
\hline Response time (Part A) & $15.05(0.22)$ & $15.27(0.60)$ \\
\hline $\begin{array}{l}\text { Response time } \\
\text { [(Part B - Part A)/(Part B + Part A)] }\end{array}$ & $0.50(0.13)$ & $0.55(0.15)$ \\
\hline Semantic relatedness (Part B) & $4.15(2.73)$ & $7.45(3.77)$ \\
\hline
\end{tabular}


Published in : Memory (2009), 17(1), 104-122

Status : Postprint (Author's version)

Unintentional inhibitory memory control

Probe recency recognition task

The performance of the two groups in the different conditions is presented in Table 4. The inhibition effect on RTs for correct responses was assessed with a 2 (group: young, elderly) X 2 (condition: Recent Negative, Nonrecent Negative) ANOVA with condition as a repeated measures factor. The analysis revealed a significant group effect $[F(1,78)=28.71, p<.0001$, ES $=.27]$, with slower RTs in elderly than young participants, and a significant condition effect $[F(1,78)=71.78, p<.0001$, ES $=.48]$, with slower RTs for Recent Negative than for Nonrecent Negative items. However, no significant interaction effect between group and condition was found $[F(1,78)=3.80, p>.05, \mathrm{ES}=.046]$. The accuracy of responses in the Recent Negative and Nonrecent Negative conditions was assessed using a similar analysis, which demonstrated a significant group effect $[F(1,78)=4.80, p<.05$, ES $=.058]$, with poorer performance in elderly participants than in young subjects. There was also a significant condition effect $[F(1,78)=6.25, p$ $<.05$, ES $=.074]$, with poorer performance for Recent Negative items, but no interaction effect between group and condition $[F(1,78)=0.04, p>.05$, ES $=.005]$. The interference effect was also measured by directly subtracting performance in the recent negative (RN) condition from that in the control (nonrecent negative, NN) condition (RN-NN/RN+NN). This interference effect was similar in the two groups of participants $[F(1,78)=0.94, p>.05$, ES $=.012]$.

Next, the effect of facilitation on response time was compared for the two groups. A 2 (group: young, elderly) X 2 (condition: Recent Positive, Nonrecent Positive) ANOVA with RT as a repeated measures factor revealed a significant group effect $[F(1,78)=36.34, p<.0001$, $\mathrm{ES}=.32]$, with elderly subjects having slower RTs than young subjects; a significant condition effect also appeared $[F(1,78)=$ $8.91, p<.005$, ES $=.10$ ], with slower RTs for Nonrecent Positive items in comparison to Recent Positive items, but no interaction between group and condition $[F(1,78)=0.81, p>.05$, ES $=.01]$. Finally, a similar ANOVA was done to determine the effect of facilitation on response accuracy. This analysis demonstrated a significant condition effect $[F(1,78)=9.82, p<.005$, ES $=.11]$, with better performance for Recent Positive than Nonrecent Positive items, but no significant group $[F(1,78)=2.45, p<.05$, ES = $.03]$ or interaction effect $[F(1,78)=0.2, p>.05$, ES $=.003]$.

Table 4. Resolution of interference in working memory task. Response time (in ms; [mean (standard deviation)]) and percentage of correct responses [mean (standard deviation)] as a function of group and condition.

\begin{tabular}{|l|c|c|}
\hline & Young subjects & Elderly subjects \\
\hline Response times & & \\
\hline Nonrecent Negative & $811(188)$ & $1025(188)$ \\
\hline Recent Negative & $881(213)$ & $1137(217)$ \\
\hline Nonrecent Positive & $858(160)$ & $1111(217)$ \\
\hline Recent Positive & $811(159)$ & $1086(260)$ \\
\hline Interference effect & $0.041(0.05)$ & $0.051(0.04)$ \\
\hline & & \\
\hline Correct responses & & \\
\hline Nonrecent Negative & $98.62(2.53)$ & $96.75(4.01)$ \\
\hline Recent Negative & $97.12(4.51)$ & $95(7.60)$ \\
\hline Nonrecent Positive & $92.50(8.70)$ & $90(12.81)$ \\
\hline Recent Positive & $96(3.79)$ & $92.6(10.19)$ \\
\hline
\end{tabular}

Retrieval-induced forgetting task

The performance of young and elderly subjects in the different conditions is presented in Table 5. A 2 (group: young, elderly) X 3 (condition: $\mathrm{U}, \mathrm{RP}+, \mathrm{RP}-$ ) ANOVA was done and demonstrated only a significant condition effect $[F(2,156)=120.33, p<.0001$, ES $=.61]$, with better performance for $\mathrm{U}$ than 
Published in : Memory (2009), 17(1), 104-122

Status : Postprint (Author's version)

RP- items (reflecting an inhibitory effect; $\mathrm{F}(1,78)=5.74, p<.05, d=.38$ ) and better performance for RP+ than $\mathrm{U}$ items (reflecting a practice effect; $\mathrm{F}(1,78)=173.52, p<.0001, d=2.08$ ). However, there was no significant group effect $[F(1,78)=2.88, p>.05$, ES $=.04]$ or interaction between group and condition $[F(2,156)=0.78, p>.1, \mathrm{ES}=.01]$.

Finally, further analyses were computed in order to insure that RIF effects we observed were not merely due to output interference (namely, the tendency of RP+ items to be recalled first; Anderson et al., 1994). The output interference account predicts lower performance for the RP- items whenever there is a robust advantage for the $\mathrm{RP}+$ items, because output interference is caused by prior recall of stronger items. Correlational analyses on our data do not support this view. Indeed, the amount of inhibition (the difference between Nrp and RP- items) was not related to the recall performance for $\mathrm{RP}+$ items $(\mathrm{r}=-.06, p$ $>.05)$ nor to the output positions of RP+ items $(r=.06, p>.05)$. Moreover, if output interference intervenes as a main explanation of the RIF effect, we would have expected a greater RIF effect for the subject who recalled an RP+ item first (namely those subjects who are supposed to experience the most output interference). A further analysis revealed that the amount of inhibition was not significantly different between the participants who produced or did not produce an $\mathrm{RP}+$ item as first exemplar $[\mathrm{t}(78)=$ $-1.84, p>.05]$. As a whole, these results suggest that output interference was not responsible for the RIF effect in our sample. (for a similar control of output interference, see Hogge, Adam \& Collette, in press a).

Table 5. Retrieval-induced forgetting task. Percentage of correct responses [mean (standard deviation)] as a function of group and condition.

\begin{tabular}{|l|c|c|}
\hline & Young subjects & Elderly subjects \\
\hline $\mathrm{U}$ & $47.19(17.45)$ & $44.22(18.58)$ \\
\hline RP+ & $79.06(15.34)$ & $70.22(20.73)$ \\
\hline RP- & $42.81(21.35)$ & $37.81(21.09)$ \\
\hline
\end{tabular}

\section{Flanker task}

Average response time and number of correct responses as a function of group and condition are indicated in Table 6. A 2 (group: young, elderly) X 3 (condition: facilitation, neutral, inhibition) ANOVA was performed on response times. This analysis demonstrated a significant group effect $[F(1,78)=39.13, p<$ .0001 , ES $=.33$, with slower RTs for elderly than young participants. There was no significant condition effect $[F(2,156)=0.7, p>.05$, ES $=.009]$ and no significant interaction between group and condition $[F(2,156)=2.45, p>.05$, ES = .03] A similar analysis (2 X 3 ANOVA; group: young, elderly; condition: facilitation, neutral, inhibition) was performed with the percentage of correct responses. This analysis demonstrated a significant group effect $[F(1,78)=9.03, p<.0005$, ES $=.10]$, with poorer performance in elderly subjects, but no significant condition effect $[F(2,156)=0.48, p>.05$, ES $=.006]$ and no significant interaction between group and condition $[F(2,156)=0.33, p>.5$, ES $=.004]$. The interference effect was also measured by directly subtracting performance in the interferent condition from that in the facilitation condition. This interference effect was similar in the two groups of participants $[F(1,78)=$ $2.30, p>.05$, ES $=.029]$. 
Published in : Memory (2009), 17(1), 104-122

Status : Postprint (Author's version)

Table 6. Flanker task. Response time (in ms; [median (standard deviation)]) and percentage of correct responses as a function of group and condition [median (standard deviation)]

\begin{tabular}{|l|c|c|}
\hline & Young subjects & Elderly subjects \\
\hline Response times & & \\
\hline Facilitation condition & $593(57)$ & $703(95)$ \\
\hline Interference condition & $602(69)$ & $698(87)$ \\
\hline Neutral condition & $589(59)$ & $701(94)$ \\
\hline Interference effect & $0.006(0.03)$ & $-0.003(0.03)$ \\
\hline & & \\
\hline Correct responses & & \\
\hline Facilitation condition & $96.44(3.71)$ & $98.52(2.09)$ \\
\hline Interference condition & $96.33(4.85)$ & $97.89(2.49)$ \\
\hline Neutral condition & $96.25(4.37)$ & $98.36(2.12)$ \\
\hline
\end{tabular}

Inhibitory performance in older participants with high vs. low memory performance

In order to confirm that the results obtained on the different tasks were really due to decreased inhibitory abilities in older participants and not to their initial lower memory performance, the group of older adults was split in two, according that their memory performance in the control / non-inhibitory condition of each task was higher or lower than the median of their group. A similar inhibitory performance in older participants exhibiting high vs. low memory scores will be indicative that decreased inhibitory effects were not due to less efficient memory abilities. Performance of high and low memory performers are presented in Table 7.

Short-term directed forgetting task. The median split for the elderly participants on the recall performance in the control (single trigram) condition was $91 \%$. The comparison of the two elderly groups ( $\mathrm{N}=20$ in each group) on the directed forgetting effect (performance of recall on inhibitory vs. control trials) did not evidence a significant difference between inhibitory performance of high and low performers $[F(1,38)=1.17, p>.05$, ES $=.03]$.

Long-term directed forgetting task. The median split for elderly participants on the recall performance for TBR items was $28 \%$. The recall performance for TBF items was similar in high $(\mathrm{N}=16)$ and low $(\mathrm{N}=24)$ performers $[F(1,38)=0.48, p>.05$, ES $=.01]$.

Hayling task. The median split for elderly participants on RTs in part A of the task was 15 seconds. The comparison of the two groups (32 high vs 8 low performers) on RTs in the inhibition part $[(\mathrm{B}-\mathrm{A}) /(\mathrm{B}+\mathrm{A})]$ did not showed a significant difference $[F(1,38)=2.99, p>.05$, ES $=.03]$. Similar results were obtained for the semantic relatedness score $[F(1,38)=4.01, p=.05$, ES $=.09]$.

Probe recency task. The RTs median split for elderly participants on nonrecent (positive and negative) items was 1022 msec. The comparison of the interference effect $(\mathrm{RN}-\mathrm{NN} / \mathrm{RN}+\mathrm{NN})$ again showed a similar performance in the high and low performers groups ( $\mathrm{N}=20$ in each) $[F(1,38)=0.17, p>$ .05 , ES = .004].

Retrieval induced forgetting task. The median split for elderly participants on recall performance for $\mathrm{RP}+$ items was $75 \%$. The comparison of the two groups ( 24 high vs. 16 low performers) on the recall performance of RP- items did not indicate a significant difference $[F(1,38)=2.06, p>.05$, ES $=.05]$.

Flanker task. The median split for elderly participants on response times in the neutral condition was 690 msec. The comparison of the two groups ( $\mathrm{N}=20$ in each group) showed a similar interference effect (interferent - facilitator items) on RTs $[F(1,38)=0.01, p>.05$, ES $=.0002]$.

These results clearly indicate that the inhibitory scores obtained by elderly participants on the six tasks administered were not driven by their initial memory performance. So, we can be confident that the specific decrease of performance in tasks requiring intentional inhibitory control of memory contents are not due to less efficient memory functioning in normal aging. 
Published in : Memory (2009), 17(1), 104-122

Status : Postprint (Author's version)

Table 7. Comparison of inhibitory control abilities of older participants showing high or low memory performance on the control (non-inhibitory) conditions of the six tasks administered

\begin{tabular}{|l|c|c|}
\hline & High performers & Low performers \\
\hline $\begin{array}{l}\text { Short-term directed forgetting } \\
\text { Directed forgetting effect } \\
\text { Long term directed forgetting }\end{array}$ & $18.50(16.95)$ & $13.33(12.93)$ \\
$\begin{array}{l}\text { TBF items (\%) } \\
\text { Hayling task }\end{array}$ & $10.07(6.16)$ & $12.04(10.19)$ \\
$\begin{array}{l}\text { Response time } \\
\text { Semantic relatedness } \\
\text { Probe recency task }\end{array}$ & $0.58(0.13)$ & $0.48(0.17)$ \\
$\begin{array}{l}\text { Interference effect } \\
\text { Retrieval induced forgetting task } \\
\text { RP- items (\%) }\end{array}$ & $6.87(3.55)$ & $9.75(3.95)$ \\
$\begin{array}{l}\text { Flanker task } \\
\text { Interference effect }\end{array}$ & $41.62(21.07)$ & $32.03(20.40)$ \\
\hline
\end{tabular}

Factorial analysis

In order to determine whether the impaired performance of elderly subjects on some memory tasks was really due to the intentional nature of the inhibitory control required, a factorial analysis was carried out on these subjects with the following variables: the percentage of correct responses in the inhibition condition of the short-term directed forgetting task, the percentage of TBF items (by comparison to TBR items) recalled on the episodic memory directed forgetting task, the score of semantic relatedness on the inhibition part of the Hayling task, the mean response times for the Recent Negative items on the probe recency task, the proportion of RP-items (in comparison to U items) on the retrieval-induced-forgetting task, and the mean response times for the interfering items on the flanker task. We expected the intentional inhibitory memory control measures to regroup on a same factor, that will be distinct from the one representing the three unintentional inhibitory measures.

The raw data on the elderly participants for these six variables were entered into a factorial analysis. Using a normalized varimax rotation, two factors emerged with eigenvalues $>1$, accounting for $54.1 \%$ of the variance. The eigenvalues for the two components were 1.80 and 1.45 respectively. The resulting two-component solution is presented in Table 8 with the individual component loading for each variable included. The tests that load heavily on component 1 are the two directed forgetting tasks and the Hayling task, while those loading on component 2 are the probe recency and flanker tasks, as well as, to a lesser extent, the retrieval-induced forgetting task.

Table 8. Pattern matrix factor loadings for the principal components exploratory factor analysis of the explicit memory tasks in elderly subjects $(\mathrm{N}=40)$

\begin{tabular}{lcc}
\hline Measures of inhibition & \multicolumn{2}{c}{ Varimax rotated component loadings } \\
\hline Intentional inhibition & Factor 1 & Factor 2 \\
Hayling & $\mathbf{0 . 7 0}$ & 0.03 \\
Short-term directed forgetting & $\mathbf{- 0 . 7 5}$ & 0.25 \\
Long-term directed forgetting & $\mathbf{0 . 6 6}$ & 0.25 \\
Unintentional inhibition & & \\
Flanker & 0.28 & $\mathbf{0 . 8 1}$ \\
Short-term probe recency & 0.04 & $\mathbf{0 . 7 7}$ \\
Retrieval-induced forgetting & -0.18 & 0.46 \\
Factor loadings exceeding 0.6 are highlighted &
\end{tabular}


Published in : Memory (2009), 17(1), 104-122

Status : Postprint (Author's version)

In order to determine if this factorial structure distinguishing between memory tasks requiring intentional or unintentional inhibitory control was specific to normal aging, a similar analysis was performed on the group of young subjects. The raw data on the young participants for the six variables were entered into a factorial analysis. Using a normalized varimax rotation, two factors emerged with eigenvalues $>1$, accounting for $49.6 \%$ of the variance. The eigenvalues for the two components were 1.53 and 1.46 respectively. The resulting two-component solution is presented in Table 9 with the individual component loading for each variable included. Contrary to results observed in older participants, the intentional and unintentional inhibitory memory control measures are not regrouped on two distinct factors. Indeed, the tests that load heavily on component 1 are the long-term directed forgetting task, the probe recency and flanker tasks, while those loading on component 2 are the Hayling task, the sort-term directed forgetting task and the retrieval-induced forgetting task.

Table 9. Pattern matrix factor loadings for the principal components exploratory factor analysis of the explicit memory tasks in young subjects $(\mathrm{N}=40)$

\begin{tabular}{lcc}
\hline & \multicolumn{2}{c}{ Varimax rotated component loadings } \\
Measures of inhibition & Factor 1 & Factor 2 \\
\hline Intentional inhibition & 0.28 & $\mathbf{- 0 . 6 1}$ \\
Hayling & 0.10 & $\mathbf{0 . 7 9}$ \\
Short-term directed forgetting & $\mathbf{0 . 7 4}$ & -0.07 \\
Long-term directed forgetting & & \\
Unintentional inhibition & $\mathbf{- 0 . 7 1}$ & 0.14 \\
Flanker & $\mathbf{- 0 . 6 3}$ & 0.04 \\
Short-term probe recency & 0.001 & $\mathbf{- 0 . 6 6}$ \\
Retrieval-induced forgetting &
\end{tabular}

\section{Discussion}

This study aimed to explore the hypothesis that some of the memory deficits associated with age are related to less efficient inhibitory control processes. We were particularly interested in assessing whether these memory deficits are limited to tasks that require intentional inhibitory control processes, or whether the deficits also affect unintentional inhibitory processes. According to our initial hypothesis, similar inhibitory performance was observed for young and elderly subjects in the three tasks assessing unintentional inhibitory memory control (the probe recency task, the retrieval-induced forgetting task and the flanker task), whereas elderly subjects demonstrated lower inhibitory abilities for the tasks that assess intentional control of the memory contents (namely, the short-term and long-term directed forgetting tasks, as well as the Hayling task). Moreover, splitting the group of elderly subjects in high and low memory performers (according that their memory performances on the non-inhibitory conditions of the tasks are below or above the median performance of the group) showed similar inhibitory effects in the high and low memory performer groups. Finally, a factorial analysis demonstrated that the performance of elderly participants (but not that of young ones) on the six tasks administered can be clearly grouped into two components, according to the intentionality of inhibitory control (although the factorial load was weaker for the retrieval-induced forgetting task).

The results obtained here extend those of previous studies in the sense that most of the inhibitory effects previously reported in the literature were replicated. Indeed, a decrease in the directed forgetting effects associated with normal aging was previously observed in working memory and episodic memory tasks when the item method was used (Andrès et al., 2004; Earles \& Kersten, 2002; Gamboz \& Russo, 2002; Hogge et al., 1998; Sego et al., 2006; Zacks et al., 1996, experiment 1). We have also observed a 
similar pattern of impaired performance on the Hayling task to that reported by Andrès and Van der Linden (2000) concerning response times on part B and the semantic relatedness score. Similarly to our results, a preserved performance on the retrieval-induced forgetting paradigm was also previously described (Aslan et al., 2007; Hogge et al., in press a). Finally, although the results in the literature are less clear-cut concerning the probe recency and flanker tasks, the presence of preserved performance associated with normal aging in these tasks has recently been shown (Collette, Schmidt, Scherrer, Adam, \& Salmon, in press; see however Jonides, Marshuetz, Smith, Reuter-Lorenz, \& Koeppe, 2000; Shaw et al., 1991).

The results we obtained are therefore clearly indicative that only aspects of intentional inhibitory memory control are less efficient in normal aging. Interestingly, a similar dissociation between intentional and unintentional suppression of memory contents processes was also observed in childhood, with unintentional inhibition developing earlier than intentional inhibition (Lechuga et al., 2006). The pattern of performance in young and elderly subjects that we observed here could explain the results of Salthouse et al. (2006), who did not succeed in finding evidence of a single construct of memory control. Indeed, the presence of a selective dysfunction in normal aging affecting some of the memory tasks administered and the grouping of these tasks on two separate factors is in agreement with the hypothesis that at least two distinct memory control processes exist, depending on the intention to suppress irrelevant information. These two inhibitory factors were not observed in the group of younger participants, indicating that this distinction between intentional and unintentional inhibitory control of memory contents is not a general characteristic of memory functioning but is specific to normal aging. The presence of less efficient intentional inhibitory processes in elderly subjects as well as the existence of two specific factors related to the intentionality of inhibitory control are consistent with some recent theories of cognitive aging. Indeed, one major theory is that the cognitive resources available to perform mental operations decline with age (Park \& Hedden, 2001), leading to greater age-related differences on tasks that require controlled processes than on those requiring automatic processes (Jennings \& Merikle, 1993; Light, 1991; Titov \& Knight, 1997).

It must nevertheless be emphasized that intentional inhibitory control processes remain available in normal aging, even if these processes seem less efficient than in young subjects. Indeed, older participants demonstrated the expected inhibitory effects on all tasks, but to a lesser extent than in the younger group on the three tasks assessing intentional inhibitory control of memory contents. These results clearly differ from those of studies that explored inhibitory functioning in frontal brain-damaged and schizophrenia populations and demonstrated reversed inhibitory effects on directed forgetting tasks (Conway \& Fthenaki, 2003; Racsmany et al., 2008). Consequently, results obtained here are indicative that normal aging is associated to a decreased efficiency of intentional inhibitory control processes, but not to a suppression of these processes. Interestingly, it was also demonstrated that this decreased efficiency cannot be attributed to the lower memory abilities of elderly participants.

However, the memory tasks we administered differed in other aspects than the intention to forget certain information. Indeed, in some tasks, inhibitory control takes place when the information is presented, while in others it occurs during the recognition or recall of information. Moreover, the tasks administered involve the running of specific working memory, episodic memory and semantic memory processes. Consequently, it seems important to examine whether the pattern of performance we observed in elderly subjects could also be explained by these task characteristics. First, with regard to the locus of inhibition, the two directed forgetting tasks, which are considered to require inhibition at the stage of encoding information (e.g., Badsen, Badsen, \& Gargano, 1993), were impaired by normal aging while the retrieval-induced forgetting and probe recency tasks, which are supposed to require inhibition during retrieval of information (Anderson, 2003; D’Esposito et al., 1999), were not. On this basis, it could be argued that normal aging is in fact associated with a specific preservation of inhibitory processes intervening during memory retrieval processes. However, other data are indicative of the presence of deficits during the retrieval of information: an increased fan effect in normal aging had previously been described (Radvansky et al., 1996, 2005) and the impaired performance observed by Andrès and Van der Linden (2000) and by ourselves on the Hayling task can also be interpreted as evidence that the access and 
retrieval of semantic information are hindered by the activation of the prepotent response. So the association in normal aging of impaired inhibitory control encoding processes and preserved inhibitory control retrieval processes does not appear to be the most appropriate explanation of the results obtained in the present study.

Second, the tasks administered differed in their involvement of working memory, episodic memory and semantic memory processes. We might suggest that our results reflect the impairment of inhibitory processes specific to one of these cognitive domains. Indeed, some authors have suggested distinguishing inhibitory processes according to the cognitive domain in which they operate and proposed the existence of specific perceptual, motor and linguistic inhibitory processes (Dempster \& Corkill, 1999a, b). Again, our results do not support this hypothesis since elderly subjects demonstrated, for each cognitive domain, impaired performance on one of the two tasks and preserved performance on the other. Moreover, other studies that directly contrasted motor and perceptual inhibitory functioning in elderly subjects did not succeed in demonstrating a selective preservation of performance in one of these two cognitive domains (Collette, Germain, \& Stawarczyk, 2007; Germain \& Collette, in press). This is another argument against the hypothesis that normal aging is associated with a selective inhibitory impairment according to cognitive domain.

Finally, a few authors have proposed that non-inhibitory mechanisms are sufficient to perform some tasks classically considered to be inhibitory (e.g., MacLeod, Dodd, Sheard, Wilson, \& Bibi, 2003; Perfect et al., 2004). Consequently, we must consider the inhibitory nature of the tasks administered in the present study. At this time, only two out of the six tasks we used have been discussed in terms of noninhibitory mechanisms: the direct forgetting task in episodic memory and the retrieval-induced forgetting paradigm (MacLeod et al., 2003; Perfect et al., 2004), and no information was available for the four remaining tasks. On this basis, it is very difficult to evaluate whether the pattern of performance of elderly participants is due to the inhibitory (or non-inhibitory) nature of some tasks. Nevertheless, in opposition to this hypothesis, discrepant results were observed for the two memory tasks previously claimed to be based on non-inhibitory processes, with impaired performance only on the episodic memory directed forgetting task (and not on the retrieval-induced forgetting task).

Consequently, the initial prediction that elderly people will present impaired inhibitory control of memory only when a voluntary suppression of information is required appears to be the most plausible account of our results. This hypothesis was developed with reference to the theoretical framework proposed by Harnishfeger (1995), which distinguishes between intentional and unintentional inhibitory processes. We wanted to determine whether this distinction can explain elderly subjects' performance on explicit memory tasks requiring inhibition. As expected, the results are indicative of less efficient inhibitory control in elderly subjects when the information to be inhibited has to be processed intentionally, regardless of the memory domain concerned. This distinction between preserved unintentional inhibitory processes and dysfunctional intentional ones during normal aging has also been observed in tasks assessing perceptual or motor inhibition. Indeed, elderly participants performed similarly to young subjects on inhibition of return and negative priming tasks (Connelly \& Hasher, 1993; Faust \& Balota, 1997; Langley, Overmier, Knopman, \& Prod'Homme, 1998; Verhaeghen \& De Meersman, 1998), which can be considered to be relatively unintentional (see nevertheless Maylor, Schlaghecken \& Watson, 2005, for an observation of impaired performance on unintentional perceptual and motor tasks), while they encountered difficulties when the task requires an inhibitory mechanism that must be triggered intentionally (such as the Stroop or antisaccade tasks; Olincy, Ros, Young, \& Freedman, 1997; Spieler et al., 1996). Moreover, this dissociation between preserved unintentional and impaired intentional inhibitory processes was confirmed in recent studies that administered these two kinds of tasks to a single group of young and elderly subjects (Andrès et al., 2008; Collette et al. 2008; Hogge, Salmon, \& Collette, in press b).

More generally, a specific impairment of intentional inhibitory processes, associated with the preservation of unintentional ones, has also been observed in frontal brain-damaged patients, and was attributed to the lesser requirement for executive control in tasks assessing unintentional processes (Conway \& Fthenaki, 2003). In that context, it can be suggested that the lower performance on intentional 
Published in : Memory (2009), 17(1), 104-122

Status : Postprint (Author's version)

inhibitory tasks in healthy elderly subjects may be due (at least in part) to a broad executive dysfunction (Fisk \& Sharp, 2004). For example, on the Hayling task, in addition to their difficulty inhibiting the prepotent response, elderly subjects may also experience difficulties in planning an efficient search strategy in semantic memory in order to find a word that is syntactically and grammatically correct but semantically unrelated to the context of the sentence.

Finally, we can ask about the exact relationships between inhibitory performance on memory tasks that we found to be completely preserved or less efficient in elderly subjects. The results of the factorial analysis are in agreement with our initial hypothesis that the (un)intentional aspect of inhibitory control of memory contents explains the pattern of memory performance of healthy elderly subjects. However, the two factors mentioned explained only $54 \%$ of the total variance on the memory tasks. Consequently, although the intentionality of the inhibitory processes required by the tasks explains the performance of elderly subjects to a significant degree, the presence or absence of inhibitory control difficulties is also highly driven by other variables that were not identified by our analyses. Difficulties isolating the specific contribution of inhibitory processes in cognitive tasks were frequently encountered in previous studies. For example, studies that were interested in determining the existence of commonalities between several inhibitory tasks generally observed lower factor loadings for these tasks than for those associated with other executive processes (Friedman et al., 2008; Miyake, Friedman, Emerson, Witzki, \& Howerter, 2000). Similarly, neuroimaging data have demonstrated that, beyond the cerebral areas commonly activated by various updating and shifting executive tasks, no other brain regions are uniquely activated by inhibitory tasks (Collette et al., 2005). These problems in finding evidence of one (or more) strong inhibitory construct(s) are probably due to the integrative nature of inhibitory functioning. Indeed, rather than a single function, inhibition probably refers to a series of mechanisms that act simultaneously on several other cognitive processes in order to increase or decrease their level of activity depending on the response to be produced. In that sense, the inhibition component associated with a specific suppression task probably depends primarily on the exact cognitive requirements of that task (for example, the amount of attentional resources necessary to perform the task, the automaticity of the processes involved, etc.).

To summarize, this study demonstrated a dissociation between preserved unintentional and less efficient intentional inhibitory control of memory contents in normal aging. The findings indicate that memory control is not a single construct, as previously claimed by Salthouse et al. (2006), but that at least two processes are involved in maintaining relevant information in an activated state in memory. Such a dissociation between intentional and unintentional inhibitory functioning in normal aging have been evidenced several times recently, and not only in the domain of memory. However, most of the time, the tasks used to explore these two aspects of inhibition differed in other ways than their intentionality (see, however, Andrès et al., 2008, experiment 1; Hogge et al., in press b). Further studies should develop inhibitory tasks that vary only in this aspect, in order to address the integrity of these two inhibitory processes in normal aging in a more controlled way and within a wider range of cognitive domains. 
Published in : Memory (2009), 17(1), 104-122

Status : Postprint (Author's version)

\section{References}

Anderson, J. R. (1974). Retrieval of propositional information from long-term memory. Cognitive Psychology, 6, 451-474.

Anderson, M. C. (2003). Rethinking interference theory: Executive control and the mechanisms of forgetting. Journal of Memory and Language, 49, 415-445.

Anderson, M. C., \& Green, C. (2001). Suppressing unwanted memories by executive control. Nature, 410, 366-369.

Anderson, M. C., Bjork, R. A., \& Bjork, E. L. (1994). Remembering can cause forgetting: Retrieval dynamics in long term memory. Journal of Experimental Psychology: Learning, Memory and Cognition, 20, 1063-1087.

Andrés, P. (in press). Equivalent part set cuing effects in younger and older adults. European Journal of Cognitive Psychology.

Andrès, P., \& Van der Linden, M. (2000). Age-related differences in supervisory attentional system functions. Journal of Gerontology: Psychological Sciences, 55B, P373-P380.

Andrés, P., Guerrini, C., Phillips, L., \& Perfect, T. (2008). Differential effects of aging on executive and automatic inhibition. Developmental Neuropsychology, 33, 101-123.

Andrès, P., Van der Linden, M., \& Parmentier, F. B. (2004). Directed forgetting in working memory: Age-related differences. Memory, 12, 248-256.

Aslan, A., Bäuml, K.-H., \& Pastötter, B. (2007). No inhibitory deficit in older adults’ episodic memory. Psychological Science, 18, 72-78.

Badsen, B. H., Badsen, D. R., \& Gargano, G. J. (1993). Directed forgetting in implicit and explicit memory tests: A comparison of methods. Journal of Experimental Psychology: Learning, Memory and Cognition, 19, 603-616.

Badsen, B.H. \& Badsen, D.R. (1998). Directed forgetting: A contrast of methods and interpretations. In J.M. Golding \& C.M. MacLeod (Eds.), Intentional forgetting. Interdisciplinary approaches (pp. 139172). Mahwah, NJ: Erlbaum Associates Publishers.

Bjork, R. A. (1970). Positive forgetting: The noninterference of items intentionally forgotten. Journal of Verbal Learning and Verbal Behavior, 9, 255-268.

Bjork, R. A. (1998). Intentional forgetting in perspective: Comments, conjectures, and some directed remembering. In J. M. Golding \& C. M. MacLeod (Eds.), Intentional forgetting: Interdisciplinary approach (pp. 433-481). Mahwah, NJ: Lawrence Erlbaum Associates.

Bjork, R. A., \& Woodward, A. E. (1973). Directed forgetting of individual words in free recall. Journal of Experimental Psychology, 99, 22-27.

Burgess, P. W., \& Shallice, T. (1996). Response suppression, initiation and strategy use following frontal lobe lesions. Neuropsychologia, 34, 263-273.

Butler, K. M., Zacks, R. T., \& Henderson, J. M. (1999). Suppression of reflexive saccades in younger and older adults: Age comparisons on an antisaccade task. Memory and Cognition, 27, 584-591.

Charlot, V., \& Feyereisen, P. (2005). Mémoire épisodique et déficit d’inhibition au cours du vieillissement cognitif: un examen de l’hypothèse frontale. L'Année Psychologique, 105, 323-357.

Cohen, J. (1988). Statistical power analysis for the behavioral sciences. Hillsdale, NJ: Lawrence Erlbaum Associates.

Collette, F., Germain, S., \& Stawarczyk, D. (2007). Effect of normal aging on perceptual and motor inhibitory processes. Paper presented at the 15th meeting of the European Society for Cognitive Psychology. Marseille, France.

Collette, F., Schmidt, C., Scherrer, C., Adam, S., \& Salmon, E. (In press). Specificity of inhibitory deficits in normal aging and Alzheimer's disease. Neurobiology of Aging.

Collette, F., Van der Linden, M., Laureys, S., Del Fiore, G., Degueldre, C., Luxen, A., et al. (2005). Exploring the unity and diversity of the neural substrates of executive functioning. Human Brain Mapping, 25, 409-423.

Connelly, S. L., \& Hasher, L. (1993). Aging and the inhibition of spatial location. Journal of Experimental Psychology: Human Perception and Performance, 19, 1238-1250. 
Connelly, S. L., Hasher, L., \& Zacks, R. (1991). Age and reading: The impact of distraction. Psychology and Aging, 6, 533-541.

Content, A., Mousty, P., \& Radeau, M. (1990). Brulex: une base de données lexicales informatisée pour le français écrit et parlé. L’Année Psychologique, 90, 551-566.

Conway, M. A., \& Fthenaki, A. (2003). Disruption of inhibitory control of memory following lesions to the frontal and temporal lobes. Cortex, 39, 667-686.

Conway, M. A., Harries, K., Noyes, J., Racsma'ny, M., \& Frankish, C. R. (2000). The disruption and dissolution of directed forgetting: Inhibitory control of memory. Journal of Memory and Language, 43, 409-430.

D’Esposito, M., Postle, B. R., Jonides, J., \& Smith, E. E. (1999). The neural substrate and temporal dynamics of interference effects in working memory as revealed by event-related functional MRI. Proceedings of the National Academy of Sciences, USA, 96, 7514-7519.

Deltour, J. J. (1993). Echelle de vocabulaire Mill Hill de J.C. Raven. Braine-le-Chateau, Belgium: Editions l'Application des Techniques Modernes.

Dempster, F. N., \& Corkill, A. J. (1999a). Individual differences in susceptibility to interference and general cognitive ability. Acta Psychologica, 101, 395-416.

Dempster, F. N., \& Corkill, A. J. (1999b). Interference and inhibition in cognition and behavior: Unifying themes for educational psychology. Educational Psychology Review, 11, 1-88.

Dubois, D. (1982). Normes de production d'exemplaires appartenant à vingt-deux catégories sémantiques, à partir d'une consigne 'classique' et d'une consigne d'imagerie. Paris: Université de Paris VIII.

Earles, J. L., \& Kersten, A. W. (2002). Directed forgetting of actions by younger and older adults. Psychonomic Bulletin \& Review, 9, 383-388.

Engle, R. W., \& Kane, K. A. (2004). Executive attention, working memory capacity, and a two-factor theory of cognitive control. In B. H. Ross (Ed.), The psychology of learning and motivation (Vol. 44, pp. 145-199). Amsterdam: Elsevier.

Faust, M. E., \& Balota, D. A. (1997). Inhibition of return and visuospatial attention in healthy older adults and individuals with dementia of the Alzheimer type. Neuropsychology, 11, 13-29.

Fisk, J. E., \& Sharp, C. A. (2004). Age-related impairment in executive functioning: Updating, inhibition, shifting and access. Journal of Clinical and Experimental Neuropsychology, 26, 874-890.

Friedman, N. P., Miyake, A., Young, S. E., Defries, J. C., Corley, R. P., \& Hewitt, J. K. (2008). Individual differences in executive functions are almost entirely genetic in origin. Journal of Experimental Psychology: General, 137, 201-225.

Gamboz, N., \& Russo, R. (2002). Evidence for age-related equivalence in the directed forgetting paradigm. Brain and Cognition, 48, 366-371.

Germain, S., \& Collette, F. (In press). Dissociation of perceptual and motor inhibitory processes in young and elderly subjects using the Simon task. Journal of the International Neuropsychological Society.

Harnishfeger, K. (1995). The development of cognitive inhibition. Theories, definitions, and research evidence. In F. N. Dempster \& C. J. Brainerd (Eds.), Interference and inhibition in cognition (pp. 176-206). London: Academic Press.

Harnishfeger, K., \& Pope, R. S. (1996). Intending to forget: The development of cognitive inhibition in directed-forgetting. Journal of Experimental Child Psychology, 62, 292-315.

Hartman, M., \& Hasher, L. (1991). Aging and suppression: Memory for previously relevant information. Psychology and Aging, 6, 587-594.

Hasher, L., \& Zacks, R. T. (1988). Working memory, comprehension, and aging: A review and a new view. In G. H. Bower (Ed.), The psychology of learning and motivation (Vol. 2, pp. 193-225). San Diego, CA: Academic Press.

Hogge, M., Adam, S., \& Collette, F. (2008). Directed forgetting and aging: The role of retrieval processes, processing speed and proactive interference. Aging, Neuropsychology and Cognition, 15, 471-491.

Hogge, M., Adam, S., \& Collette, F. (In press a). Retrieval induced forgetting in normal aging. Journal of Neuropsychology. 
Hogge, M., Salmon, E., \& Collette, F. (In press b). Interference and negative priming in normal aging and in mild Alzheimer's disease. Psychologica Belgica.

Houx, P. J., Jolles, J., \& Vreeling, F. W. (1993). Aging effects assessed with the Stroop color word test in childhood, adulthood, and aging. Experimental Aging Research, 19, 209-224.

Jennings, J. M., \& Merikle, P. M. (1993). Automatic versus intentional uses of memory: Aging, attention, and control. Psychology and Aging, 8, 283-293.

Johnson, H. M. (1994). Processes of successful intentional forgetting. Psychological Bulletin, 116, 274292.

Jonides, J., Marshuetz, C., Smith, E. E., Reuter-Lorenz, P. A., \& Koeppe, R. A. (2000). Age differences in behavior and PET activation reveal differences in interference resolution in verbal working memory. Journal of Cognitive Neuroscience, 12, 188-196.

Jonides, J., Smith, E. E., Marshuetz, C., Koeppe, R. A., \& Reuter-Lorenz, P. A. (1998). Inhibition in verbal working memory revealed by brain activation. Proceedings of the National Academy of Sciences, USA, 95, 8410-8413.

Kane, M. J., \& Engle, R. W. (2000). Working-memory capacity, proactive interference, and divided attention: Limits on long-term memory retrieval. Journal of Experimental Psychology: Learning, Memory and Cognition, 26, 336-358.

Kramer, A. F., Humphrey, D. G., Larish, J. F., Logan, G., \& Strayer, D. (1994). Aging and inhibition: Beyond a unitary view of inhibitory processing in attention. Psychology and Aging, 9, 491-512.

Kwong See, S. T., \& Ryan, E. (1995). Cognitive mediation of adult age differences in language performance. Psychology and Aging, 10, 458-468.

Langley, L. K., Overmier, J. B., Knopman, D. S., \& Prod'Homme, M. S. (1998). Inhibition and habituation: Preserved mechanisms of attentional selection in aging and Alzheimer's disease. Neuropsychology, 12, 353-366.

Lechuga, M., T., Moreno, V., Pelegrina, S., Gomez-Ariza, C. J., \& Bajo Teresa, M. (2006). Age differences in memory control: Evidence from updating and retrieval practice tasks. Acta Psychologica, 123, 279-298.

Light, L. (1991). Memory and aging: Four hypotheses in search of data. Annual Review of Psychology, 42, 333-376.

MacLeod, C. M. (1989). Directed forgetting affects both direct and indirect tests of memory. Journal of Experimental Psychology: Learning, Memory and Cognition, 15, 13-21.

MacLeod, C. M. (1998). Directed forgetting: The human memory literature. In J. M. Golding \& C. M. MacLeod (Eds.), Intentional forgetting: Interdisciplinary approaches. (pp. 1-57). Mahwah, NJ: Lawrence Erlbaum Associates.

MacLeod, C. M., Dodd, M. D., Sheard, E. D., Wilson, D. E., \& Bibi, U. (2003). In opposition to inhibition. In B. H. Ross (Ed.), The psychology of learning and motivation. (Vol. 43, pp. 163-214). San Diego, CA: Academic Press.

Marsh, E.J., Dolan, P.O., Balota, D.A. \& Roediger III, H.L. (2004) Part-set cuing effects in younger and older adults. Psychology and Aging, 19, 131-144.

Mattis, S. (1973). Dementia Rating Scale. Windsor, ON: NFER-Nelson.

May, C. P., \& Hasher, L. (1998). Synchrony effects in inhibitory control over though and action. Journal of Experimental Psychology: Human Perception and Performance, 24, 363-379.

Maylor, E. A., Schlaghecken, F., \& Watson, D. G. (2005). Aging and inhibitory processes in memory, attentional, and motor tasks. In R. W. Engle, G. Sedek, U. von Hecker, \& D. N. McIntosh (Eds.), Cognitive limitations in aging and psychopathology (pp. 313-345). New York: Cambridge University Press.

Miyake, A., Friedman, N. P., Emerson, M. J., Witzki, A. H., \& Howerter, A. (2000). The unity and diversity of executive functions and their contribution to complex 'frontal lobe' tasks: A latent variable analysis. Cognitive Psychology, 41, 49-100. 
Monsch, A. U., Bondi, M. W., Salmon, D. P., Butters, N., Thal, L. J., Hansen, L. A., et al. (1995). Clinical validity of the Mattis dementia rating scale in detecting dementia of the Alzheimer type. Archives of Neurology, 52, 899-504.

Nielson, K. A., Langenecker, S. A., \& Garavan, H. (2002). Differences in the functional neuroanatomy of inhibitory control across the adult life span. Psychology and Aging, 17, 56-71.

Nigg, J. T. (2000). On inhibition/disinhibition in developmental psychopathology: Views from cognitive and personality psychology and a working inhibition taxonomy. Psychological Bulletin, 126, 220246.

Olincy, A., Ros, R., Young, D. A., \& Freedman, R. (1997). Age diminishes performance on an antisaccade eye movement task. Neurobiology of Aging, 18, 483-487.

Paller, K. (1990). Recall and stem-completion priming have different electrophysiological correlates and are modified differently by directed forgetting. Journal of Experimental Psychology: Learning, Memory, and Motivation, 16, 1021-1032.

Park, D. C., Lautenschlager, G., Smith, D. A., Earles, J. L., Frieske, D., Zwahr, M., et al. (1996). Mediators of long-term memory performance across the life span. Psychology and Aging, 11, 621637.

Park, D., \& Hedden, T. (2001). Working memory and aging. In M. Naveh-Benjamin, M. Moscovitch, \& H. L. I. Roediger (Eds.), Perspectives on human memory and cognitive aging. Essays in honour of Fergus Craik (pp. 148-160). Hove: Psychology Press.

Paz-Caballero, M. D., Menor, J. \& Jiménez, J. M. (2004). Predictive validity of event-related potentials (ERPs) in relation to the directed forgetting effects. Clinical Neurophysiology, 115, 369-377.

Perfect, T. J., Stark, L. J., Tree, J. J., Moulin, C. J. A., Ahmed, L., \& Hutter, R. (2004). Transfer appropriate forgetting: The cue-dependent nature of retrieval induced forgetting. Journal of Memory and Language, 51, 399-417.

Racsmany, M., Conway, M.A., Garab, E.A., Cimmer, C., Janka, Z. Kurimay, T., Pléh, C, \& Szendi, I. (2008). Disrupted memory inhibition in schizophrenia. Schizophrenia Research, 101, 218-224.

Radvansky, G. A., Zacks, R. T., \& Hasher, L. (1996). Fact retrieval in younger and older adults. The role of mental models. Psychology and Aging, 11, 258-271.

Radvansky, G. A., Zacks, R. T., \& Hasher, L. (2005). Age and inhibition: The retrieval of situation models. Journal of Gerontology: Psychological Sciences, 60B, P276-P278.

Reed, H. (1970). Studies of interference process in short-term memory. Journal of Experimental Psychology, 84, 452-457.

Salthouse, T. A. (1996). The processing-speed theory of adult age difference in cognition. Psychological Review, 3, 403-428.

Salthouse, T. A., Siedlecki, K. L., \& Krueger, L. E. (2006). An individual differences analysis of memory control. Journal of Memory and Language, 55, 102-125.

Schneider, W., Eschman, A., \& Zuccolotto, A. (2002). E-Prime user's guide. Pittsburgh, PA: Psychology Software Tools Inc.

Sego, S. A., Golding, J. M., \& Gottlob, L. R. (2006). Directed forgetting in older adults using the item and list methods. Aging, Neuropsychology and Cognition, 13, 95-114.

Shaw, R. J. (1991). Age-related increases in the effects of automatic semantic activation. Psychology and Aging, 6, 595-604.

Spieler, D. H., Balota, D. A., \& Faust, M. E. (1996). Stroop performance in healthy younger and older adults and in individuals with dementia of the Alzheimer's type. Journal of Experimental Psychology, 22, 461-479.

Swinney, D., \& Prather, P. (1989). On the comprehension of lexical ambiguity by young children: Investigations into the development of mental modularity. In D. Corfein (Ed.), Resolving semantic ambiguity. New York: Springer-Verlag.

Titov, N., \& Knight, R. G. (1997). Adult age differences in controlled and automatic memory processing. Psychology and Aging, 12, 565-573. 
Van der Linden, M., Hupet, M., Feyereisen, P., Schelstraete, M., Bestgen, Y., Bruyer, R., et al. (1999). Cognitive mediators of age-related differences in language comprehension and verbal memory performance. Aging, Neuropsychology and Cognition, 6, 32-55.

Verhaeghen, P., \& De Meersman, L. (1998). Aging and the negative priming effect: A meta-analysis. Psychology and Aging, 13, 435-444.

Wylie, G.R., Foxe, J.J., Taylor, T.L. (2008). Forgetting as an active process: an FMRI investigation of item-method-directed forgetting. Cerebral Cortex, 18, 670-682.

Zacks, R. T., \& Hasher, L. (1994). Directed ignoring: Inhibitory regulation of working memory. In D. Dagenbach \& T. H. Carr (Eds.), Inhibitory processes in attention, memory and language (pp. 241264). San Diego, CA: Academic Press.

Zacks, R. T., Hasher, L., \& Li, K. Z. H. (2000). Human memory. In F. I. M. Craik \& T. A. Salthouse (Eds.), Handbook of cognitive aging and cognition (pp. 293-357). Mahwah, NJ: Lawrence Erlbaum Associates.

Zacks, R. T., Radvansky, G., \& Hasher, L. (1996). Studies of directed forgetting in older adults. Journal of Experimental Psychology: Learning, Memory and Cognition, 22, 143-156.

Zellner, M., \& Bäuml, K.-H. (2006). Inhibitory deficits in older adults: List-method directed forgetting revisited. Journal of Experimental Psychology: Learning, Memory and Cognition, 32, 290-300. 
Published in : Memory (2009), 17(1), 104-122

Status : Postprint (Author's version)

\section{Footnotes}

1. Although there exists a debate in the literature concerning the exact processes involved in the item method of the directed forgetting paradigm (selective rehearsal of TBR items [Basden et al., 1993; Bjork, 1970; Bjork \& Woodward, 1973; Paller, 1990] vs. attentional inhibition of TBF items [Zacks \& Hasher, 1994; Zacks, Radvansky, \& Hasher, 1996], the item method was selected because a series of brain-related data were recently provided to support the intervention of attentional inhibitory processes when this procedure is used. Indeed, psycho-physiological experiments demonstrated that the successful processing of TBF items is associated with specific event-related potential (ERP) activity and that the recognitionrelated ERPs for TBR and TBF items differ qualitatively and quantitatively, especially in the frontal areas (Paz-Caballero, Menor, \& Jiménez, 2004; Ullsperger, Mecklinger, \& Müller, 2000). Moreover, neuroimaging data also showed that intentional forgetting depends on neural substrates distinct from those involved in unintentional forgetting and intentional remembering (Wylie et al., 2007). The involvement of frontal areas during intentional forgetting in these studies suggests that inhibitory control processes are critical in the method item of the directed forgetting paradigm. 